\title{
Market Failure In African Agricultural Marketing Systems: An Econometric Testing And Analysis Of Market Efficiency
}

Gbolahan S. Osho, (E-mail: oshogs@tsu.edu), Texas Southern University

\begin{abstract}
The last few years have seen substantial revivals of interest in the determinants of economic growth in Africa, especially in the Sub-Saharan Africa. This paper provides an econometric model that help to examine the impact of market share, interest rate and non-economic factors such as external shocks, structural adjustment policies on the GDP of Sub-Saharan Africa. Economic development data covering the period of 1970 to 2004 was used in estimation with ordinary least square (OLS). The results indicate that market share is the crucial element for low GDP in this region of the world and that high interest rate lowers the GDP and therefore impedes market growth. The econometric analysis showed the failure of interest rate to rise with the GDP has been the result of changes in fundamental determinants.
\end{abstract}

\section{INTRODUCTION}

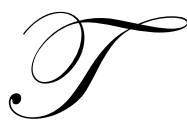

he last few years have seen substantial revivals of interest in the determinants of economic growth in Africa, especially in the Sub-Saharan Africa. Many economists are interested in finding out why this region of the world has a poorly developed economy, or has experienced virtually little or no real economic growth. Most countries in Sub-Saharan Africa are densely populated with heterogeneous endowments of resources. After the colonial period, agricultural exports were the backbone of their economy. Agricultural products accounted for a significant share of exports. Despite this sound prospect for growth, with the regions' abundant resources, however, this region is still the poorest part of the world economy; hence prospects for economic growth, especially market improvement are not encouraging.

Sub-Saharan Africa's declining importance in global trade is now seen primarily due to its inability to remain competitive in international markets. If Africa merely retained its 1972-2001 shares for major products its exports would now be $75 \%$ ( $\$ 11$ billion) higher especially for Sub-Saharan Africa. In order to improve market structure and performance over the past few decades, Sub-Saharan Africa has implemented various programs, economic packages, and external protection, but still faces a free fall economy. In fact, Organization for Economic Co-Operation and Development trade preferences made market access conditions for Africa more favorable than they did for many other exporters. In contrast, Sub-Saharan Africa's own trade barriers are now seen to be considerably higher than those of most other developing countries particularly those that launched sustained export-oriented industrialization drives.

In an attempt to better understand the source of distortions and market failure in Sub-Saharan Africa: whether the shock is from changing market share or from changing interest rate or from non-economic factor such as impacts of external shocks, including structural adjustment policies hence, this paper will estimate the responsiveness of regional GDP to variations in market share, and interest rate on economic development data covering the period of 1970 to 2004. In addition, this research will verify whether those highly recommended programs and packages designed by the World Bank, and other institutions like Food Agriculture Organization, and International Monetary Fund, have helped to reinvigorate this regions' economy and determined how institutionally effective are those policies recommendations. Finally, it will also provide recommendations for policies that can generate more stable market system and marketing environment in Sub-Sahara Africa. 


\section{MODEL SPECIFICATION}

Ghura and Grennes (1993) pooled time-series and cross-section data for thirty-three countries in sub-Saharan Africa confirm the negative relationship between the real exchange rate misalignment and economic performance (economic growth, imports, exports, saving, and investment). Macroeconomic instability also slows growth and other indicators of performance. Higher levels of macroeconomic instability accompany higher levels of misalignment. Both lower levels of real exchange rate misalignment and instability lead to better economic performance. The Edwards model of real exchange rate determination performs well for the region. Black-market premiers tend to show a greater degree of misalignment in real exchange rate than alternative measures.

Oczkowski (1999) developed a theoretically consistent econometric technique which models the bargaining environment and the determination of price and quantity transacted in a market dominated by a single seller and buyer. The generalized Nash bargaining framework and limited dependent variable econometric techniques are integrated to achieve this end. Besides exogenous shifters, only data on price and quantity transacted are needed to model unobserved bargaining limits, bargaining strengths and outcome profits/surpluses. The coking coal trade between Japan and Australia is analyzed to illustrate the technique. Based on either a profit or surplus measure of the gains from trade, Australia's division of the gains from trade is predicted to have increased significantly over time.

Benabou (1999) used two unifying models and an empirical exercise that presents and extends the main theories linking income distribution and growth, as well as the relevant empirical evidence. The first model integrates the political economy and imperfect capital markets theories. It allows for explicit departures from perfect democracy and embodies the tradeoff between the growth costs and benefits of redistribution through taxes, and land reform. The second model is a growth version of the prisoner's dilemma that captures the essence of theories where sociopolitical conflict reduces the security of property rights, thereby discouraging accumulation. The economy's growth rate is shown to fall with interest groups' rent-seeking abilities, as well as with the gap between rich and poor.

Fielding (1996) used a game-theoretic model to explore the positive and normative economics of government policy choices in a monetary union. If individual governments have control over fiscal policy, then the noncooperative solution to the model is not Pareto optimal. Moreover, the distribution of welfare typically favors largest members of the union. These results are compared with the experience of the West African Monetary Union, which exhibits many of the stylized facts predicted by the model.

\section{DATA AND ESTIMATION PROCEDURE}

An important measure of overall economics and market performance is the total amount of goods and services produced within the national economy in a given year called the Gross Domestic Product (GDP). The SubSaharan African GDP measure the production of goods and services by the factories and offices located in various countries across the region. Various countries in this region of the world has developed and maintained on accounting systems intended to provide a record of the domestic economy over time. These accounting systems were designed to facilitate policy decisions and provide a basic for understanding economic fluctuations, make decisions and track market performance. The total value of production equals the total value of expenditure:

$G D P=C+I+G+(X-M)$

The total amount of expenditure in the economy for a given period is assigned to one of five categories: $C$ is consumption, $I$ is the investment, $G$ is government purchases, $X$ is total exports and $M$ is total imports

Government consumption spending represents spending on goods and services (defense, judicial system, education, etc); it therefore excludes transfer payments such as unemployment benefits. Net exports are equal to the difference between exports and imports of goods and services. Net exports are also defined as the trade balance of the country which could be negative or positive. 
The available data is collected from various Ministry of Finance, Department of Commerce, and Economic Community for West Africa States data set including gross domestic product, consumption, interest rates, government spending, market share and exchange rate. The following models are then estimated:

$G D P=\gamma_{1}+\gamma_{2} M k t+\gamma_{3} I r t+\gamma_{4} G o v t+\gamma_{5} E T R+\gamma_{6} I n v t+\varepsilon_{t}$

$G D P_{t}=\gamma_{1}+\gamma_{2} M k t+\gamma_{3} I r t+\gamma_{4} G o v t+\gamma_{5} E T R+\gamma_{6} I n v t+\gamma_{6} G D P_{t-1}+\varepsilon_{t}$

Where $G D P_{T-1}$ is lag period of gross domestic product, Mkt is the Market share of trade, Govt is government spending, Irt is Interest rate, ERT is the Exchange rate, Invt is the Investment level, and $\varepsilon_{t}$ is error term. The estimated gross domestic product in the above model is tested for joint condition mean and variance test and using the following models;

$\varepsilon_{t}=\gamma_{1}+\gamma_{2} M k t+\gamma_{3} I r t+\gamma_{4}$ Govt $+\gamma_{5} E T R+\gamma_{6} I n v t+\gamma_{7} T+\gamma_{8} Y H A T+\varepsilon_{t}$

$\varepsilon_{t}^{2}=\gamma_{1}+\gamma_{2} M k t+\gamma_{3} I r t+\gamma_{4}$ Govt $+\gamma_{5} E T R+\gamma_{6} I n v t+\gamma_{7} T+\gamma_{8} Y H A T^{2}+\varepsilon_{t-1}^{2}$

\section{SYSTEM MISSPECIFICATION TESTS}

From the data output, Individual tests of functional form, heteroskedasticity, and autocorrelation and parameter stability were conducted for both models. Joint tests of overall mean test and overall variance test were also conducted. The tests indicate whether the ordinary least squares (OLS) yields linearly unbiased estimators and minimum variance. However, one should not ignore the impact of investment on the GDP, as statistically insignificant does not always imply economic insignificance (McCloskey and Ziliak). Equation (2) yields biased estimators and the estimators are not efficient. However, OLS assumptions of normality, no autocorrelation, parameter stability, and homoskedasticity were in violation. Therefore, equation (2) was corrected for heteroskedasticity and re-estimated.

Parameter estimates are presented in Table 1 and from the equation (2), the coefficient of $M K T$ variable indicates that an increase in a unit will result in an increase in annual gross domestic products. The value of coefficient of determination $R^{2}$ equal to (0.9990) indicates that three independent variables explain $99.87 \%$ of the total dependent variable (GDP) in the regression equation. The remaining $(100-99.90=0.10 \%)$ of the variation of gross domestic products is due to the random change or possibly the presence of the other variables not includes in this regression equation. In addition $R^{2}$ and adjusted $R^{2}$ both are asymptotically equal. The $F$-value is used to test the hypothesis that the independent variable explains a significant proportion of the variation in the dependent variable GDP.

The Durbin-Watson statistic tests for first-order autocorrelation, the value ranges from 0to 4 . From the model summary, the Durbin-Watson statistic is 1.952 indicates the possible presence of positive autocorrelation. However, the DW test is subject to several drawbacks and hence not recommended; it often gives inconclusive results since it is invalid if lagged dependent variables are present, and is not applicable if error follows a higher order autoregressive process. Therefore, an alternative test, Breusch-Godfrey and Serial Correlation LM test was conducted.

The correlation coefficients between each of the possible pairs of explanatory (independent) variables are shown in the table. Note that high degree of inter correlation (in absolute value terms) between MKT and GOVT, ETR and $I N V, G O V T$ and $I N V$, suggests that the estimate of these regression coefficients may be unreliable. From the regression, the presence of multicolinearlity also means that the t-test is no longer a reliable indicator of the statistic significance of the individual explanatory variable and this equation presents heteroskedasticity.

The present of heteroskedasticity causes the estimate of the variance of the error terms to be dependent on the particular set of values of the independent variable that was chosen. Another set of observations yield a different estimates of this variance. As a result, tests of the statistical significance of the individual regression coefficients $(t$ - 
test) and overall explanatory power of the regression equation proves to be misleading. By ignoring the presence of heteroskedasticity and applying OLS procedure, some of the properties of the estimators are altered. OLS estimators are still unbiased and consistent. Forecasts based on them are also unbiased and consistent. Estimates and forecasts, however, are inefficient and hence are no longer BLUE. Because the estimated variances and covariance of the estimates are biased and inconsistent, test of hypothesis are not valid any more. Therefore, we use estimated EGLS procedure in SAS to correct the problem of heteroskedasticity and autocorrelation in this model.

Market share represents a large portion of the GDP and is the largest component of GDP. Hence, Market Volume is extremely vital to the movements of the economic growth. Investment is the most volatile component of GDP change as investment decisions by economic agents are based on expectations of future economic growth, profits and interest rates. In particular, during a recovery from a recession, investment tends to grow much faster than GDP while when the economy contracts investment falls much more sharply than GDP. Government spending tends to be a constant share of GDP and is not very volatile.

\section{EMPIRICAL RESULT AND IMPLICATIONS}

The appropriate linear equation of these GDP is modeled by equation (2) and the estimated parameters are unbiased, consistent, but not efficient because the collected data is time-series. Empirical study defined the nonlinearly functional form for GDP model. Another factor that affects the GDP is the interest rate. The higher the interest rate, the lower the GDP if the financial institutions like the IMF increase the interest rates of borrowing countries like the Sub-Saharan, such high interest rate tends to distort the GDP thereby lowering the market development in this region of the world. The Financial Institutions for instance introduces a lot of financial programs to the borrowing countries in the Sub-Saharan Africa without proper monitoring of such programs and without adequate consideration of the feasibility of those programs to the economies of this region. International Monetary Fund programs were introduced in various Sub-Saharan African countries such as Ghana, Nigeria, Mali, and Senegal this however, has not helped the economies to gain moment due to the expectation of such benefits.

The lack of proper monitor of implementation and expectation of such program are reflected in the GDP through low market share and high interest rate. This affects the positive expectation of such financial support. Therefore in order to improve market performance and success rate, the World Bank must become more selective and do a better job of understanding, which environments are promising for reform and which are not in this region of the world.

\section{SUMMARY AND CONCLUSIONS}

This study measures the impact of market shares, government spending, exchange rates, investments, and interest rates on the GDP of Sub-Saharan Africa to determine the source of distortions and market failure in SubSaharan Africa. The results indicate that market share is the crucial element for low GDP in this region of the world. In addition, investment and government follow usual trend as predicated by macroeconomic theory. However, one important feature of this study is the role of interest rates. The result shows that a high interest rate lowers the GDP and therefore impedes market growth. The econometric analysis showed the failure of interest rate to rise with the GDP has been the result of changes in fundamental determinants.

In addition, it is highly recommended that the World Bank and other institutions like Food Agriculture Organization, and International Monetary Fund should weigh policy recommendations before providing loans to this region of the world. Finally, there is a need for these organizations to go into coalition with the countries in this region. This would help to see the implementation of these programs since history and social norms are equally important in evaluating market economy of any region of the world (Geoffrey M. Hodgson). 
Table 1.0 Estimated Parameter for GDP Component in the Sub-Saharan Africa, 1970-2004

\begin{tabular}{|c|c|}
\hline Variable & Estimated Coefficient \\
\hline$M K T$ & 8.899411 \\
& $(0.0670)$ \\
\hline$I R T$ & 0.021944 \\
$(0.0260)$ \\
\hline$G O V T$ & -0.057381 \\
& $(0.0443)$ \\
\hline$E T R$ & 0.458620 \\
& $(0.0576)$ \\
\hline$I N V$ & 3.607736 \\
& $(0.0039)$ \\
\hline
\end{tabular}

Note: The numbers in parenthesis are standard errors

\section{REFERENCE}

1. Fielding, D. Asymmetries in the Behavior of Members of a Monetary Union: A Game-Theoretic Model with an Application to West Africa. Journal of African Economies 5(October 1996): 343-65.

2. Ghura, D., and Grennes, T. J. The Real Exchange Rate and Macroeconomic Performance in Sub-Saharan Africa. Journal of Development Economics 42 (October 1993): 155-74.

3. Goetz, Stephan J. A Selectivity Model of Household Food Marketing Behavior in Sub-Saharan Africa. Amer. J. Agr. Econ. 74, (May 1992): 444-52.

4. Gyimah-Brempong, K., and Gyapong, A. O. Exchange Rate Distortion and Economic Growth in Ghana. International Economic Journal 7(May 1993): 59-74.

5. Hodgson, Geoffrey M. The Approach of Institutional Economics. Journal of Economics (March 1998): 166192.

6. Logan, I. B., and Mengisteab, K. IMF-World Bank Adjustment and Structural Transformation in SubSaharan Africa. Economic Geography 69(January 1993): 1-24.

7. McCloskey, N., and T.S. Ziliak. The Standard Error of Regressions. J. Econ. Lit. 35(march 19996): 97-114.

8. Oczkowski, E. An Econometric Analysis of the Bilateral Monopoly Model. Economic Modeling. v16, n1 (January 1999): 53-69.

9. $\quad$ Paarlberg, D. The Case for Institutional Economics. Amer. J. Agr. Econ. 75(August 1993): 823-827.

10. Ruttan V. W., and Hayami Y. Toward a Theory of Induced Institutional Innovation. The Journal of development studies. 20(July 1984): 15-18.

11. Sandholm, William H. An Evolutionary Approach to Congestion. Northwestern University Center for Mathematical Studies in Economics and Management Science, copyright (c) 1998 Cambridge University Press.

12. Seidmann, Daniel J.; and Winter, Eyal. A Theory of Gradual Coalition Formation. Rev. Econ. Stud 65(October 1998): 793-815.

13. Tiller, Emerson H., and Spiller, Pablo T. Strategic Instruments: Legal Structure and Political Games in Administrative Law. Journal of Law, Economics, and Organization v15, n2 (July 1999): 349-77. 
International Business \& Economics Research Journal - September 2007

Volume 6, Number 9

\section{NOTES}

